\title{
Design and Realization of Reliability Enhancement Test for Breech Mechanism of Large-Caliber Guns
}

\author{
Lijun Cao*, Tong Xu, Chao Ding, Guibo Yu, and Shuhai Wang \\ Department of Gun Engineering, Army Engineering University, Shijiazhuang, 050003, China
}

\begin{abstract}
To address the issue that conducting a reliability enhancement test for large-caliber guns is impossible based on actual equipment, a new kind of enhancement test bed for the breech mechanism is designed and established. By measuring the extreme working stress of the test bed, enhancement test stress and enhancement stress levels are determined. The cross sections of single stress enhancement tests and comprehensive stress enhancement tests are designed. The cartridge extracting process is selected to excite the potential failures. The wear of the shaft arm of the shell stop and the wear of the arm of the cocking shaft are measured and analyzed based on finite element analysis and micro examination tests. The practical failure process is illustrated. Under the combined action of impact sliding coupling wear and abrasive particle wear, there are flakes, pan furrows, and holes on the part surfaces, which result in outline variation and force transmission failure. The research idea of this paper provides a new kind of failure mode analysis method for large-caliber guns.
\end{abstract}

Keywords: reliability enhancement test; breech mechanism; wear; simulation

(Submitted on October 12, 2018; Revised on November 15, 2018; Accepted on December 17, 2018)

(C) 2019 Totem Publisher, Inc. All rights reserved.

\section{Introduction}

The breech mechanism is the key subsystem of large-caliber guns, and it serves to close the breech, fire the ammunition, and extract the cartridge case [1]. Usually, the breech mechanism of large-caliber guns is semiautomatic vertical slidingwedge type. It consists of the breechblock assembly, semiautomatic device, firing device, safety device, shell stop device, and extractor assembly. The whole number of essential parts of the breech mechanism is more than one hundred [1-2]. The heaviest part is the breechblock, whose weight is more than $76 \mathrm{~kg}$. The lightest part weighs less than $0.01 \mathrm{~kg}$. A tremendous impulse force acts on the parts of the breech mechanism in a short time, which results in significant wear, fatigue, and collisions. Statistical data show that the fault rate of the breech mechanism is more than 50\% for the firepower system [3-4]. In order to improve the gun's operational reliability, the breech mechanism is taken as a research object to carry out reliability enhancement tests and motivate the underlying weaknesses rapidly in this paper. Micro-texture anti-friction design and solid lubrication technology were developed to improve the specific weakness and realize reliability growth.

Traditional reliability tests and evaluation technologies require long periods and mass money [5-6]. The reliability enhancement test is a new kind of method to inspire the part invalidation of the breech mechanism. It provides a more rigorous test condition than the natural service condition by increasing test stress. Reliability enhancement tests can accelerate the part invalidation process to reveal reliability weakness segments in a short time [5, 7]. Appropriate improvement and optimization technologies can be adopted to improve the reliability weakness segments. Presently, research on reliability enhancement tests of electronic products has acquired remarkable academic and applied achievements [8]. However, research on reliability enhancement tests of mechanical products is limited [9]. In particular, there are still no systematic and profound research findings regarding reliability enhance tests of large-caliber guns, due to the lack of corresponding reliability enhancement test theory, technology, and equipment. This paper takes the breech mechanism of a large-caliber gun as a research object to generalize feasible reliability enhancement methods and explore effective reliability growth technologies.

\footnotetext{
* Corresponding author.

E-mail address: caolijun_jun@163.com
} 


\section{Establishment of Reliability Enhancement Test Bed for Breech Mechanism}

The enhancement test stress of the breech mechanism depends on the counter-recoil breechblock-opening velocity. Increasing the charge in firing and raising the striking velocity from the muzzle modify the counter-recoil breechblockopening velocity and dynamic parameters of the breech mechanism by small amplitudes [10]. The reliability enhancement test bed is designed and established to carry out reliability enhancement tests of the breech mechanism. Compared with service firing, reliability enhancement tests based on test bed reduce dangers and increase the efficiency-cost ratio.

The functions of the test bed are to finish the breechblock opening and close tests for the breech mechanism. Specific functions include:

(1) It is applicable for impacting breechblock-opening guns, and it can finish automatic breechblock-opening, automatic breechblock-closing, and continuous breechblock opening and closing.

(2) It can simulate the breechblock opening and closing processes of live firing and provide basis for reliability enhancement tests and accelerated life tests of the breech mechanism.

(3) The impact parameters are adjustable to the normal working condition and different enhancement test conditions.

(4) It has a crawl mode and series mode. The crawl mode is used to control the manual breechblock opening and closing processes. The series mode is used to control the automatic continuous breechblock opening and closing processes.

\subsection{Technical Indexes}

According to the dynamic parameters of live firing tests and the periods of breechblock opening and closing, the test bed technical indexes of reliability enhancement tests are as follows:

(1) The drive force is more than $2427.4 \mathrm{~N}$; the drive velocity is more than $0.85 \mathrm{~m} / \mathrm{s}$.

(2) The test frequency of automatic breechblock opening and closing is 3-5 degrees per minute.

(3) The no-failure continuous breechblock opening and closing number of the reliability enhancement test bed is more than 500 .

(4) The power of the automatic pushing bar is $24 \mathrm{~V}$ and direct current, the maximal pushing force is $100 \mathrm{~kg}$, the pushing velocity is $10 \mathrm{~mm} / \mathrm{s}$, and the maximum extension length is $90 \mathrm{~mm}$.

(5) The weight of the single mass block of the breechblock-opening mechanism is $15.3 \mathrm{~kg}$.

\subsection{Tables Structural Composition}

The reliability enhancement test bed of the breech mechanism is mechanical, electrical, hydraulic integrated test equipment, which consists of body, breech mechanism, supporting and fixing device of breech, power output device, breechblockopening device, breechblock-closing device, and control and test device. The breech mechanism roots in a kind of service large-caliber gun. The hydraulic system adopts the valves produced by Beijing Hade Corporation. The control system adopts the programmable logic controller of EC10-1410BRA type. The displacement measurement of the breechblock adopts a potentiometer sensor of PT1DC type. Its measuring range is 50 inches. Its sensitivity is $3.9370 \mathrm{mV} / \mathrm{mm}$. The dynamic characteristic measuring of the load sliding table adopts laser sensors of ZLDS100 type. Its measuring range is $1510 \mathrm{~mm}$. Its sampling frequency is $9.4 \mathrm{kHz}$. Its wave length is $660 \mathrm{~nm}$. When the reliability enhancement test bed of the breech mechanism begins to work, the power output device provides breechblock-opening power, the breechblock-opening plate crashes the crank in its moving process towards breech-end, and the percussion force drives the breechblock moving downward. The breechblock-closing process is completed by the breechblock-closing device.

\section{Reliability Enhancement Test Bed for Breech Mechanism}

Based on the reliability enhancement test principle and the reliability enhancement test bed of the breech mechanism, the working extreme stress can be analyzed and the intensified test stress can be determined. 


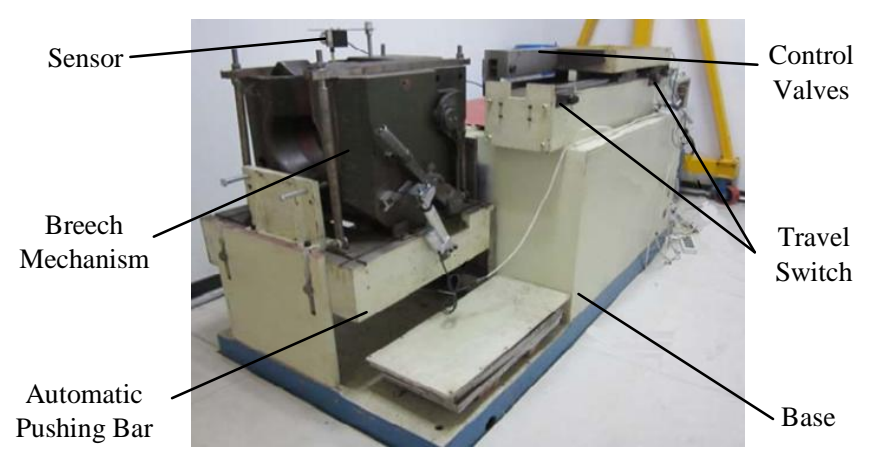

Figure 1. Reliability enhancement test bed of breech mechanism

\subsection{Extreme Working Stress Measurement of Test Bed}

\subsubsection{Driving Mass}

According to the masses of the breechblock-opening plate, support arm, load sliding table, and mass block on the reliability enhancement test bed, the maximum value of the driving mass is $149 \mathrm{~kg}$ and the minimum value of the driving mass is $72.5 \mathrm{~kg}$. The intermediate values include four steps, which are determined by the number of driving masses.

\subsubsection{Pressure of Overflow Valve}

When there is no load on the breechblock-opening device, adjust the pressure control knob of the overflow valve and measure the pressure range of the hydraulic pressure. The result of the pressure range of the overflow valve is $0 \sim 10 \mathrm{Mpa}$.

\subsubsection{Driving Velocity}

According to the extreme pressure value of the overflow valve, modify the flow in different hydraulic cylinders by rotating the pressure control knob. The laser sensors measure the displacement and velocity of the load sliding table. Figure 2 and Figure 3 are the measurement results.

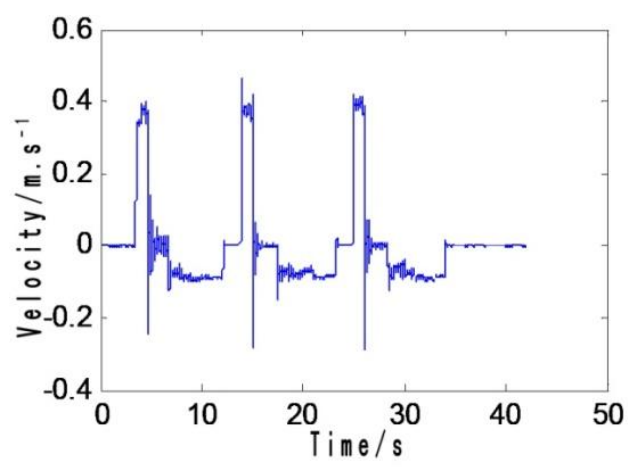

Figure 2. Displacement curve of load sliding table

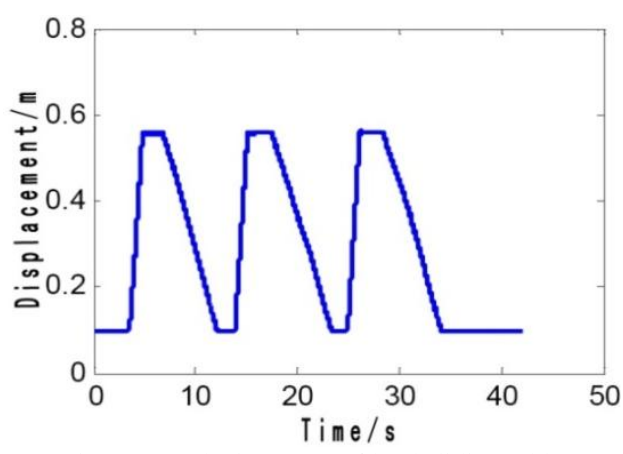

Figure 3. Velocity curve of load sliding table 
Figure 2 shows the displacement curves of three shuttle processes of the load sliding table. Because there is a given distance between the laser sensor and the load sliding table, the initial displacement is not zero. The actual displacement is $0.470 \mathrm{~m}$, which is consistent with the breechblock-opening range. Figure 3 shows that there are obvious waves on the velocity curve. Especially when the load sliding table touches the terminal limit switch, the electromagnetic valve breaks off, the hydraulic system lies off, the velocity of the load sliding table drops suddenly, and there are obvious peak impulses. However, there are minor waves in the breechblock-opening process and breechblock-closing process. The equalization of the breechblock-opening velocity is $0.38 \mathrm{~m} / \mathrm{s}$.

Adjust the knob of the flow regulating valve and measure the velocity curves of the load sliding table (Figure 4 and Figure 5). In Figure 4, the velocity equalization of the load sliding table is $0.49 \mathrm{~m} / \mathrm{s}$. Then, adjust the pressure of the overflow valve to $5 \mathrm{MPa}$ and measure the velocity of the load sliding table when the hatch of the flow regulating valve is maximized. In Figure 5, the velocity equalization of the load sliding table is $0.892 \mathrm{~m} / \mathrm{s}$. The above measurement results show that when the hydraulic pressures are different and the hatches are same, the driving velocities of the enhancement test bed are also different, and the velocity control of the flow regulating valve is influenced by the pressure of the overflow valve. By adjusting the hydraulic pressure continuously, when the pressure of overflow valve is $10 \mathrm{MPa}$ and the knob of the flow regulating valve is maximized, the maximum driving velocity of breechblock-opening is $1.269 \mathrm{~m} / \mathrm{s}$, which illustrates that the maximum current velocity of the hydraulic system decreases because of the loads and other middle floating resistances. Considering the above influencing factors, the driving velocity range of the enhancement test bed is $0 \sim 1.269 \mathrm{~m} / \mathrm{s}$.

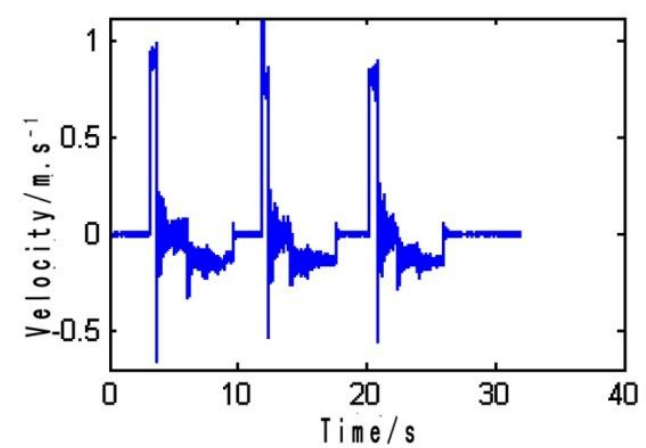

Figure 4. Velocity curve of load sliding table when $P=2.5 \mathrm{MPa}$

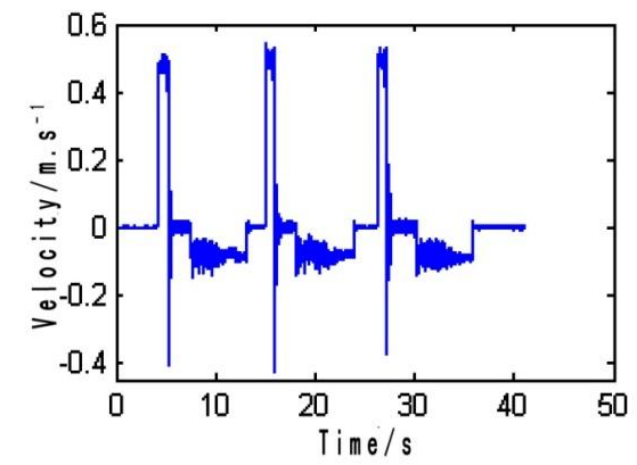

Figure 5. Velocity curve of load sliding table when $P=5.0 \mathrm{MPa}$

\subsubsection{Driving Distance}

The driving distance only influences the acceleration process of the load sliding table from stillness to steady speed and has no effects on the breechblock-opening process. Therefore, the distance between the front edge of the breechblock plate and the curved surface of the crank should be guaranteed, and the velocity of the load sliding table should be stable. The distance is determined by the position of the rear limit switch, which is fixed at $0.295 \mathrm{~m}$.

\subsection{Determination of Enhancement Test Stress}

According to the measurement results of the reliability enhancement test, take the breechblock-opening indexes (the driving mass is $72.5 \mathrm{~kg}$, the pressure of the overflow valve is $3 \mathrm{MPa}$, and the driving velocity is $0.49 \mathrm{~m} / \mathrm{s}$ ) as primary test parameters, 
increase them in the breechblock-opening and breechblock-closing tests, and measure the displacement and the velocity of the breechblock. They are shown in Figure 6.

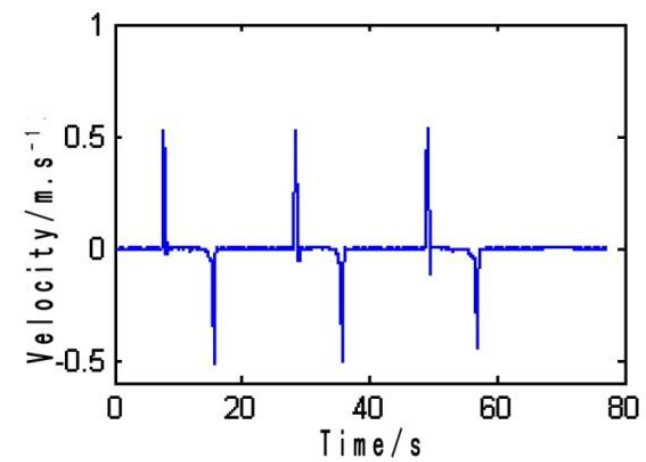

Figure 6. Breechblock velocity under primary parameters

Figure 7 shows that the increase in the driving mass has little influence on the decrease in the breechblock velocity, there are no obvious difference among different velocity peaks, and the maximum velocities of the two different driving masses are $0.525 \mathrm{~m} / \mathrm{s}$ and $0.556 \mathrm{~m} / \mathrm{s}$. Figure 8 and Figure 9 show that with an increase in the pressure of the overflow valve and the driving velocity, the breechblock velocity decreases obviously. If the breechblock velocity increases, the wear-outfailure parts will increase the relative sliding velocities and working stresses and the fatigue-out-failure parts will increase the dynamic loads. For example, the wear extent of the cocking cam and the impact of the closing spring will increase, which are also the stress enhancement processes. Therefore, for reliability enhancement tests of the breech mechanism, the enhancement test stresses are the driving mass, the driving velocity, and the pressure of the overflow valve.

The setting pressure of the overflow valve is not directly acting on the piston rod, which directly influences the flow of the hydraulic cylinder and the driving velocity of the piston rod. In the subsequent reliability enhancement test process, if the enhancement effects of the overflow valve are not considered and the extreme pressure is set as 10MPa directly, the test working conditions are consistent with the actual working conditions.

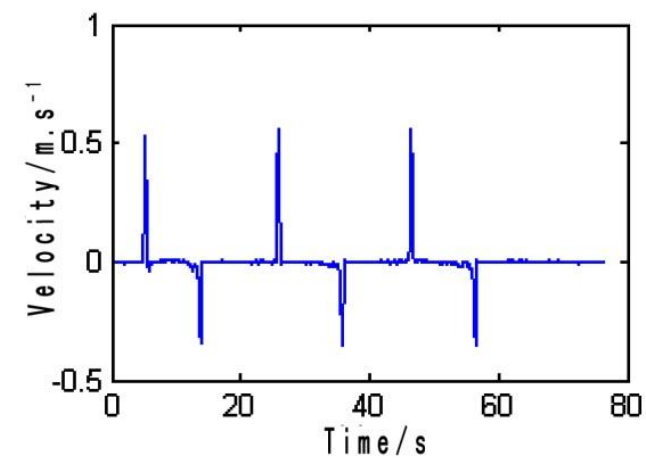

Figure 7. Breechblock velocity when $M=118.4 \mathrm{~kg}$

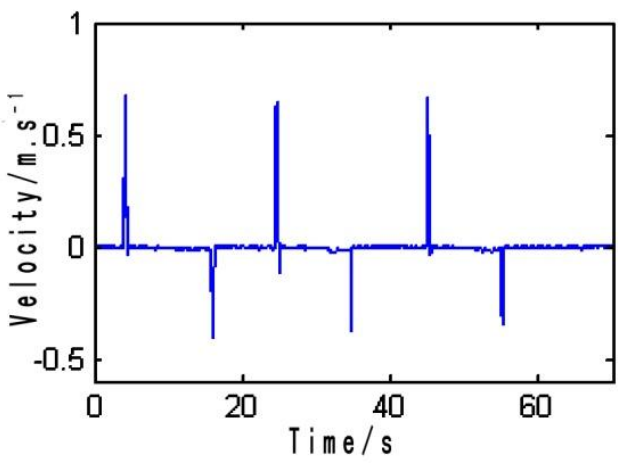

Figure 8 . Breechblock velocity when $P=5 \mathrm{MPa}$ 


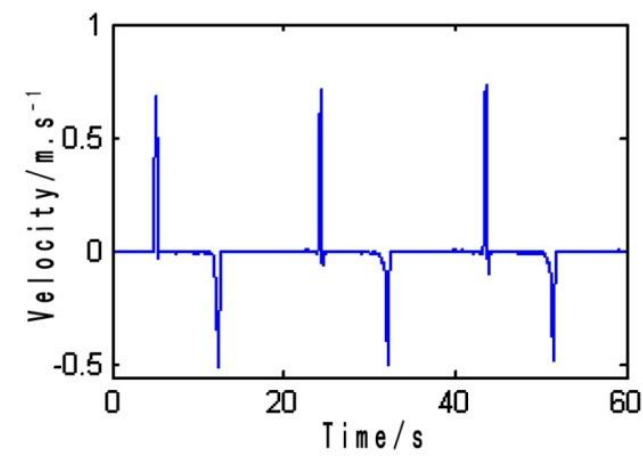

Figure 9. Breechblock velocity when $V=0.73 \mathrm{~m} / \mathrm{s}$

\subsection{Determination of Enhancement Stress Level}

The normal stress levels can be determined by the simulated working conditions. The driving mass is $72.5 \mathrm{~kg}$, and the driving velocity is $1.124 \mathrm{~m} / \mathrm{s}$. If the pressure of the overflow valve is set as $10 \mathrm{MPa}$, increasing the mass number and adjusting the hatch area of the flow regulating valve will enlarge the stress levels of the reliability enhancement test. In the extreme range of the working stress, select the enhancement test stress levels as shown in Table 1. The driving mass is determined by the mass number. The driving velocity is determined by the velocity of the load sliding table under different hatch areas of the flow regulating valve.

Table 1. Stress level of enhancement test
\begin{tabular}{|c|c|c|c|c|c|}
\hline \multirow{2}{*}{ Test stress } & Normal stress level & \multicolumn{4}{|c|}{ Enhancement stress level } \\
\cline { 2 - 6 } & 0 & 1 & 2 & 3 & 4 \\
\hline The driving mass $(\mathrm{kg})$ & 72.5 & 87.8 & 103.1 & 118.4 & 133.7 \\
\hline The driving velocity $(\mathrm{m} / \mathrm{s})$ & 1.124 & 1.183 & 1.21 & 1.252 & 1.269 \\
\hline
\end{tabular}

\section{Reliability Enhancement Test of Breech Mechanism}

Reliability enhancement tests under different stress levels can be carried out based on the enhancement test bed. Considering the number limitation of test objects, the usual stress load operation of equivalent step is adopted. Firstly, the step stress test of driving mass is accomplished. Then, the step stress test of driving velocity is accomplished. Finally, the comprehensive stress test is accomplished. Based on limited test conditions, most possible potential defects can be excited.

\subsection{Section Design of Enhancement Test under Single Stress Level}

When the driving force and the driving velocity are given, the modification of the driving mass will influence the momentum between the breechblock-opening plate and crank directly. With an increase in the driving mass, the momentum of breechblock-opening will also increase. The impulse when the breechblock-opening plate impacts the crank will increase immediately. The dynamic load and the working stress will also increase to excite latent defects. When the other stress levels are constant, only change the driving mass to perform the breechblock opening and closing tests. The continuous number of enhancement tests is 50. The corresponding test section is shown in Figure 10, where "a" denotes the continuous test process of breechblock opening and closing and "b" denotes the motion detection of the test mechanism.

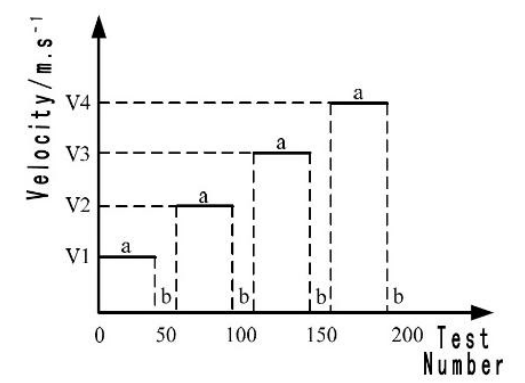

Figure 10. Breechblock velocity when $P=5 \mathrm{MPa}$ 
The driving velocity can also influence the momentum between the breechblock-opening plate and the crank. With an increase in the driving velocity, the breechblock-opening momentum will also increase. When the other stress levels are normal, only change the stress level of the driving velocity to proceed with the breechblock opening and closing test [11]. The continuous number of enhancement tests is also 50. The corresponding test section is shown in Figure 11.

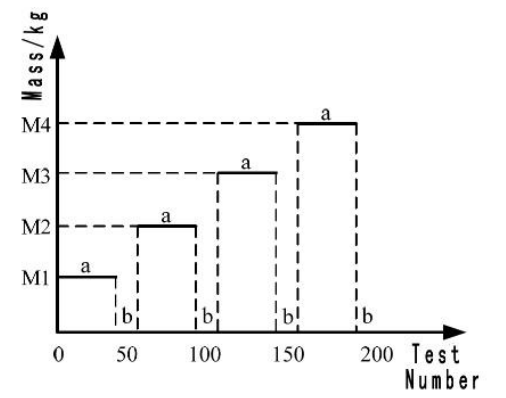

Figure 11. Breechblock velocity when $V=0.73 \mathrm{~m} / \mathrm{s}$

\subsection{Section Design of Enhancement Test under Comprehensive Stress Levels}

In order to strengthen the test effects, reliability enhancement tests under comprehensive stress levels are carried out based on the stress level ranges in Table 1. Change two stress levels of the enhancement test to accomplish an all-array test of two elements and four levels. The corresponding test section is shown in Figure 12 [12-13]. The test number of every stress level is 50. Detect the mechanism action after each test. If there is no fault, continue the enhancement test according to the test section. If there is still no fault after the tests of all stress levels, continue the enhancement test under the maximum stress level M4-V4.

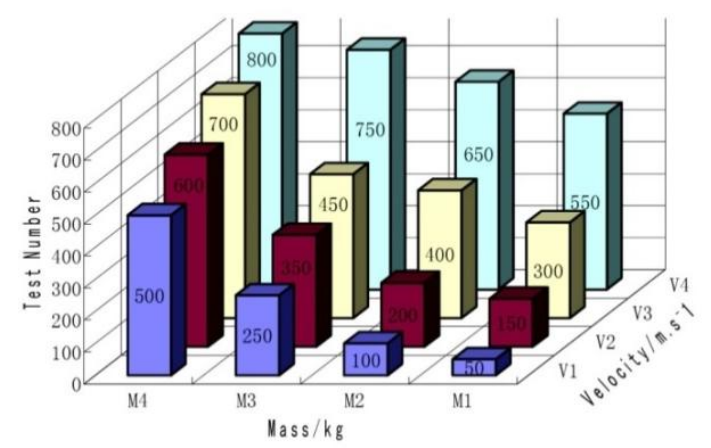

Figure 12. Enhancement test section under comprehensive stresses

\subsection{Implementation of Reliability Enhancement Test}

According to the test sections of single stress level and comprehensive stress levels, carry out the reliability enhancement test of the breech mechanism and count the test number using a magnetic counter [14]. Figure 13 shows that the breechblock-opening plate slides the inclined plane of the crank in the recovery process of the load sliding table after opening the breechblock. Figure 14 shows the magnetic counter and the counting process. The test numbers under different stress levels are shown in Table 2.

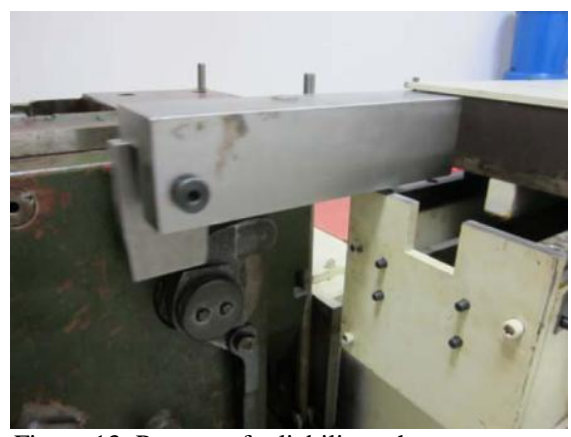

Figure 13. Process of reliability enhancement test 


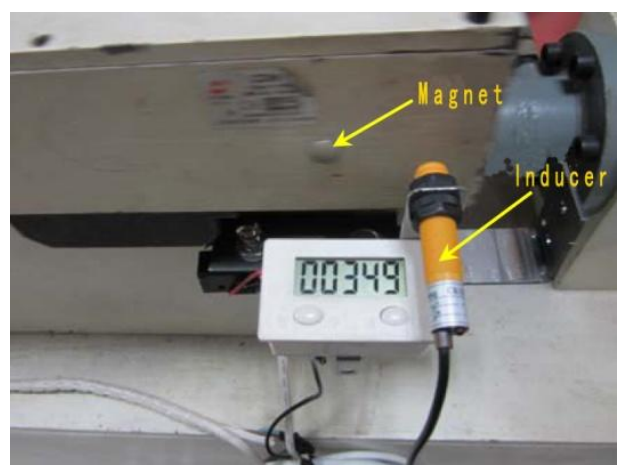

Figure 14. Magnetic counter and the counting process

Table 2. Results of the reliability enhancement test for breech mechanism

\begin{tabular}{|c|c|c|c|c|c|}
\hline \multirow{2}{*}{ Driving velocity } & \multicolumn{5}{|c|}{ Driving mass } \\
\cline { 2 - 6 } & M0 & M1 & M2 & M3 & M4 \\
\hline V0 & - & 50 & 50 & 50 & 50 \\
\hline V1 & 50 & 50 & 50 & 50 & 27 \\
\hline V2 & 50 & 50 & 50 & 50 & \\
\hline V3 & 50 & 50 & 50 & 50 & \\
\hline V4 & 50 & & & & \\
\hline
\end{tabular}

The comprehensive stress test is carried out after the single stress test. The fault of being unable to extract the cartridge case occurs in the $27^{\text {th }}$ comprehensive test of the M4-V1 stress level. If there is the same fault in the service firing process, the gun will be unable to load the next projectile and cartridge case. By means of the reliability enhancement test of the breech mechanism, the potential faults can be excited. According to the flow of the reliability enhancement test, the corresponding fault reasons and the potential flaws should be analyzed in order to provide theoretical basis for flaw elimination and reliability improvement.

Fault mode and effect analysis is carried out according to the above fault phenomenon. There are two kinds of fault modes that lead to fault occurrence, one is the mechanical wear between the shaft arm of the shell stop and the arm of cocking shaft, while the other is the screw overhang of the shell stop. By means of fault detection, the actual fault reason is the mechanical wear between the shaft arm of the shell stop and the arm of cocking shaft. Decompose the shell stop device and check the shaft arm of the shell stop and the arm of the cocking shaft. There are obvious scratches along the sliding direction on the surfaces. The imaginable line squares in Figure 15 and Figure 16 show that there is superficial organization exfoliation on the shaft arm of the shell stop, which illustrates that the wear consequence of the shaft arm of the shell stop is more severe than that of the cocking arm of the shell stop. In order to judge the wear extent exactly, an electronic analytical balance type of EX324ZH is used to weigh the worn part. Compare the worn part and the new part, and average three sequential measurement results. The average results are shown in Table 3.

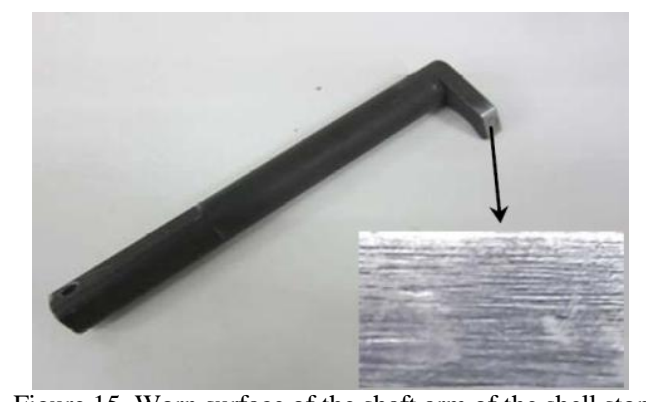

Figure 15. Worn surface of the shaft arm of the shell stop

Table 3 shows that the quality of the tow worn parts is less than that of the new parts. Therefore, the wear of the shaft arm of the shell stop and the arm of the cocking shaft results in the cartridge clamping stagnation. Replace new parts of the shaft arm of the shell stop and the arm of the cocking shaft to test the breechblock opening and closing functions. The test bed of the breech mechanism recovers normal actions, which certifies the fault analysis conclusions. 


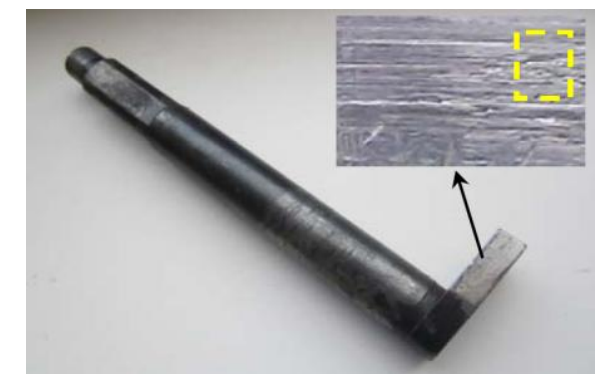

Figure 16. Worn surface of the arm of the cocking shaft

Table 3. Comparison between worn part and new part

\begin{tabular}{|c|c|c|c|c|}
\hline \multirow{2}{*}{ Item } & \multicolumn{2}{|c|}{ Shaft arm of shell stop } & \multicolumn{2}{c|}{ Arm of cocking shaft } \\
\cline { 2 - 5 } & Worn part & New part & Worn part & New part \\
\hline Weight & 213.01323 & 215.66747 & 228.03660 & 229.73337 \\
\hline
\end{tabular}

\section{Research on Wear Failure Mechanics based on Microscopic Analysis}

The existing literature and research findings on part wear of the breech mechanism concentrate on fault analysis caused by wear or wear life evaluation. Wear failure mechanics are not analyzed in detail. This paper analyzes the part's wear process from surface topography, microstructure variation, etc.

Transmit the solid models of the breech mechanism into the finite element software to establish the finite element models and analyze the mutual dynamical process of the shaft arm of the shell stop and the arm of the cocking shaft. The simulation results include the equivalent stress distribution at different times. Figure 17 is the stress distribution when $t=0.0023 \mathrm{~s}$. Select ten nodes at the same interval along the arm surface in the sliding direction. Based on the finite element analysis, the maximum equivalent stress distribution curve of all nodes on the part surface can be obtained and are shown in Figure 18.

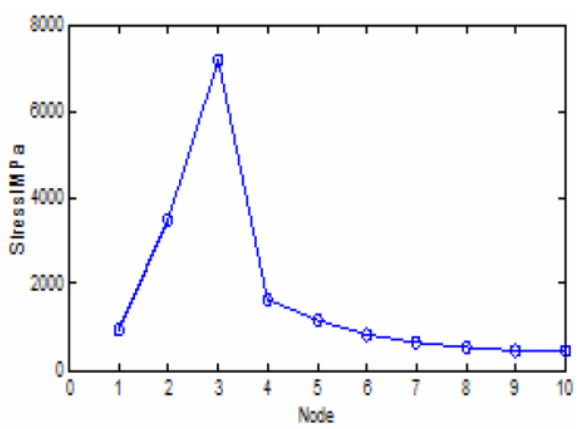

Figure 17. Stress cloud figure when $t=0.0023 \mathrm{~s}$

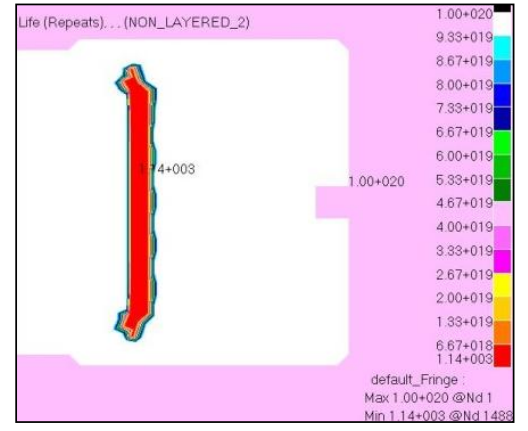

Figure 18. Maximum stress distribution curve on part surface

Figure 18 shows that the maximum equivalent stress of node 1 to node 5 is greater than the material ultimate strength $835 \mathrm{MPa}$. The stresses of node 2 and node 3 are greater than this ultimate strength, which illustrates that there is severe flake and plastic deformation in this area. The maximum equivalent stress of node 6 is less than the ultimate strength but greater 
than the yield strength $685 \mathrm{MPa}$, which illustrates that there is plastic deformation around the node. The maximum equivalent stress of node 7 to node 10 is less than the yield strength. The variation process is gentle.

The material of the shaft arm of the shell stop is PCrMo, whose partial element composition is shown in Table 4. To analyze and compare the variation and difference of the surface pattern and microstructure before and after wear of the shaft arm of the shell stop, sample from the worn area and unworn area.

\begin{tabular}{|c|c|c|c|c|c|}
\hline Element & $\mathrm{C}$ & $\mathrm{Si}$ & $\mathrm{Mn}$ & $\mathrm{Cr}$ & $\mathrm{Ni}$ \\
\hline Percentage composition & $0.32 \sim 0.40$ & $0.17 \sim 0.37$ & $0.25 \sim 0.5$ & $0.9 \sim 1.3$ & $\leq 0.5$ \\
\hline Element & Mo & $\mathrm{Cu}$ & $\mathrm{P}$ & S & \\
\hline Percentage composition & $0.2 \sim 0.3$ & $\leq 0.2$ & $\leq 0.025$ & $\leq 0.025$ & \\
\hline
\end{tabular}

The sample surface hardness of the worn area and unworn area is shown in Table 5. It shows that the hardness of the unworn area has narrower variation range and better compatibility. However, the hardness of the worn area increases obviously. Combined with the above stress analysis, there is plastic deformation and hardening of the surface metal layer caused by collision and friction between parts.

Table 5. Sample surface hardness of worn area and unworn area
\begin{tabular}{|c|c|c|c|c|}
\hline Test surface & 1 & 2 & 3 & 4 \\
\hline Worn area & 563.1 & 535.7 & 558.3 & 527.6 \\
\hline Unworn area & 458.2 & 458.7 & 452.3 & 463.1 \\
\hline Test surface & 5 & 6 & 7 & \\
\hline Worn area & 559.9 & 565.1 & 559.5 & \\
\hline Unworn area & 457.1 & 461.9 & 461.9 & \\
\hline
\end{tabular}

Figure 19 presents the SEM micrographs, which show there are flakes, pan furrows, and holes. The pan furrows are along the relative movement direction. The massive flakes form notches. The abrasive dusts embed into the worn surface. Therefore, the initial wear process is impact sliding coupling wear, and the later wear process is abrasive particle wear [1516]. Abrasive particle wear usually results in severe surface damage.

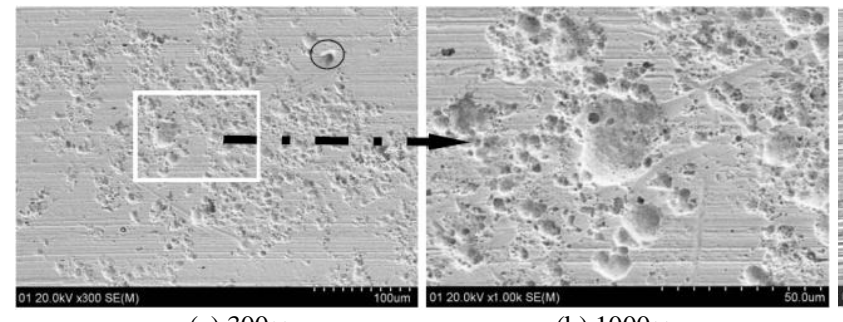

(a) $300 x$
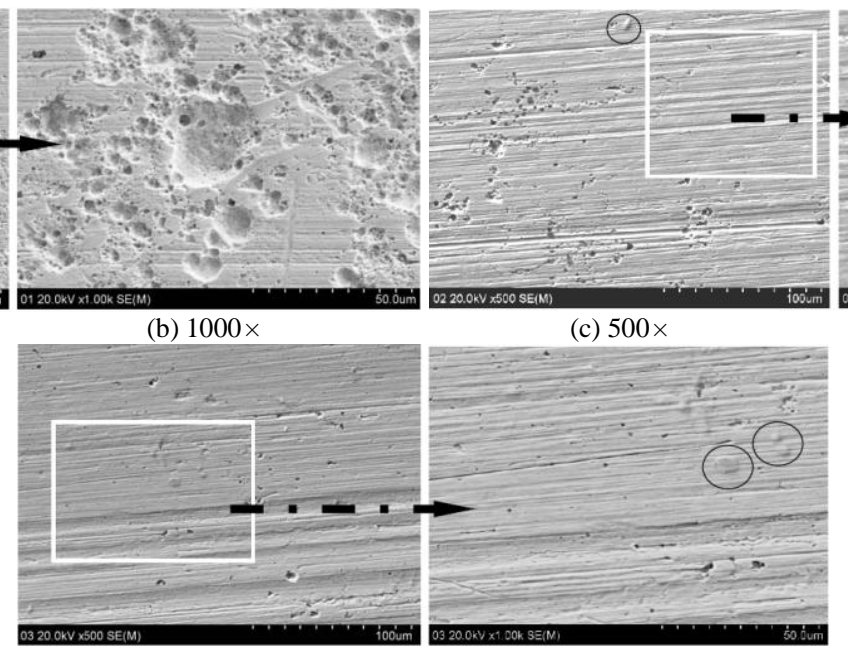

(e) $500 x$ (c) $500 \times$

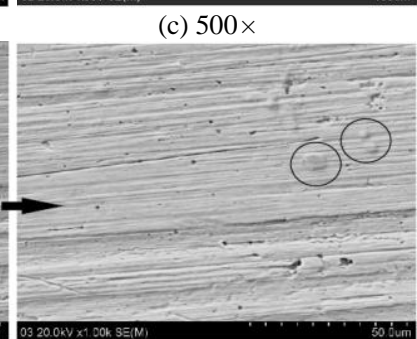

(f) $1000 \times$

Figure 19. SEM Micrograph

Based on the surface pattern analysis, composition analysis, cross section organization analysis, and hardness analysis, the following conclusions can be generalized:

(1) There is obvious plastic deformation on the surface metal layer caused by collision and friction, which results in the hardness increase of the surface and cross section. 
(2) The initial wear process is impact sliding coupling wear. The later wear process is abrasive particle wear.

\section{Conclusions}

In order to improve the reliability of the breech mechanism for large-caliber guns, a reliability enhancement test bed is designed and established according to the actual equipment. Test stress and stress levels are determined based on the extreme measurement results and enhancement effectiveness. The cross sections of single stress enhancement tests and comprehensive stress enhancement tests are designed. By means of the reliability enhancement test, the fault of impossible extracting is excited. Microscopic observations and analysis illustrate the wear failure mechanics. Impact sliding coupling wear and abrasive particle wear are the prime failure reasons of the shaft arm of the shell stop and the arm of the cocking shaft.

\section{References}

1. X. J. Shao, Z. B. He, J. H. Liu, and G. Tian, "Kinematic and Dynamic Simulation of Breech Mechanism based on Virtual Prototype," Fire Control \& Command Control, Vol. 39, No. 7, pp. 14-17, July 2014

2. S. H. Hu, M. H. Zhang, W. Fu, and X. L. Liu, "Dynamic Characteristics of Extractor System in Artillery Vertical Wedge Breechblock," Explosion and Shock Waves, Vol. 37, No. 2, pp. 221-228, March 2017

3. Y. F. Yang, J. Zheng, C. C. Di, and D. Wang, "Discussion on Reliability Enhancement Test Scheme of Gun Mechanical Systems," Equipment Environmental Engineering, Vol. 13, No. 2, pp. 134-138, April 2016

4. Y. F. Yang, J. Zheng, C. C. Di, H. K. Wang, and S. Wang, "Research on Reliability Enhancement Testing Technology of Breech Firing Mechanism," Fire Control \& Command Control, Vol. 41, No. 7, pp. 175-178, July 2016

5. M. Chao, P. Jing, and M. Wei, "Study on Reliability Enhancement Testing for InSb Focal Plane Array Detector," in Proceedings of the International Symposium on Photoelectronic Detection and Imaging, pp. 221-227, Beijing, China, August 2011

6. G. K. Hobbs, “Accelerated Reliability Engineering: HALT and HASS,” John Wiley and Sons Inc., San Francisco, 2000

7. Z. F. Fan, X. L. Qi, and J. K. Liu, "Comprehension and Implementation of Reliability Enhancement Testing for Ammunition," in Proceedings of the International Conference of Information Science and Management Engineering, pp. 347-350, Xiamen, China, November 2015

8. C. G. Guleryuz and J. E. Krzanowski, "Mechanisms of Self-Lubrication in Patterned TiN Coatings Containing Solid Lubricant Microreservoirs," Surface and Coatings Technology, Vol. 204, No. 4, pp. 2392-2399, April 2014

9. H. Mclean, "The Application of Accelerated Testing Methods and Theory HALT, HASS and HASA," QualMark Corporation, New York, 2000

10. Z. B. Cai, J. F. Peng, H. Qian, L. C. Tang, and M. H. Zhu, "Impact Fretting Wear Behaviour of Alloy 690 Tubes in Dry and Deionized Water Conditions," Chinese Journal of Mechanical Engineering, Vol. 30, No. 1, pp. 819-828, January 2017

11. G. Z. Pan, W. W. Liu, X. B. Li, J. F. Yang, T. Yuan, and Z. T. Yuan, "Research on the Application of Reliability Enhancement Test Technology in Servo System," Electronic Product Reliability and Environmental Testing, Vol. 36, No. 1, pp. 1-7, January 2018

12. H. F. Sun, H. F. Hu, S. L. Zhai, and Z. Y. Song, "The Application of Reliability Enhancement Testing Technology in the Development of Aerospace Equipment," Aerospace Control, Vol. 35, No. 5, pp. 92-97, May 2017

13. Y. Sato, A. Iwabuchi, and M. Uchidate, "Dynamic Corrosion Properties of Impact-Fretting Wear in High-Temperature Pure Water," Wear, Vol. 330, No. 1, pp. 182-192, January 2015

14. L. Yang, M. Zhou, and S. Chen, "Heat Transfer Enhancement with Mixing Vane Spacers using the Field Synergy Principle," Chinese Journal of Mechanical Engineering, Vol. 30, No. 1, pp. 200-206, January 2016

15. X. Y. Chen, J. P. Fan, and X. Y. Bian, "Theoretical Analysis of Non-Probabilistic Reliability based on Interval Model," Acta Mechanica Solida Sinica, Vol. 30, No. 2, pp. 638-646, February 2017

16. X. K. Wang, Z. W. Zhang, and Y. L. Zhong, "Research on the Application of Reliability Enhancement Test in Electromechanical Products," Electronic Product Reliability and Environmental Testing, Vol. 34, No. 5, pp. 51-56, May 2016 